\title{
Una sintaxis del más allá: transgresión y religiosidad popular judía en un caso argentino
}

A syntax beyond: transgression and popular religion in a Jewish Argentine case

Dra. Elisa Cohen de Chervonagura elisa@chervonagura.com.ar Universidad de Tucumán

Argentina

\section{Resumen}

El presente artículo aborda el estudio de un caso de santidad popular en la comunidad judía de Tucumán (Argentina), seleccionado porque manifiesta una sacralidad alternativa muy influida por prácticas similares provenientes del contexto no judío, siempre proclive a reverenciar las "almas milagrosas" y legitimar la categoría de santo popular. Asimismo se revisan otras situaciones similares dentro de la tradición judaica, señalándose la importancia que tiene el culto de Malka Saltz porque evidencia la incorporación de elementos propios de la imaginería visual del noroeste argentino, constituyendo así un fenómeno inusual de mestizaje debido al proceso concreto de inserción cultural de la comunidad judía en el contexto general de la región.

Palabras Clave: Religión - Mujer - Santidad - Mausoleo

\begin{abstract}
The present article approaches the study of a popular sacredness case in the Jewish community of Tucumán (Argentina), selected due to the fact that it reveals an alternative sacredness very much influenced by similar practices coming from the non- Jewish context, always prone to reverend "miraculous souls" and legitimize the category of popular saint. At the same time, other similar situations into the Jewish tradition are revised pointing out the importance that Malka Saltz's cult possesses since it reveals the incorporation of elements proper to the visual imagery of Argentine Northwest constituting an unusual phenomenon of crossbreeding because of the concrete process of cultural insertion of the Jewish community in the general context of the region.
\end{abstract}

Keywords: Religion - Woman - Sacredness - Mausoleum 


\section{Introducción}

Por lo general el estudio y la investigación acerca de la santidad popular profundizan en la vida y milagros de alguien reverenciado por su trayectoria y origen. Sin embargo, en esta ponencia voy a analizar algunos aspectos del caso de Malka Saltz en la provincia de Tucumán (Argentina), fenómeno difundido solo a través de los datos que ofrece la transmisión oral por lo que pasa a constituir un hecho especial y sobresaliente.

Cabe aclarar que esta presentación forma parte de una investigación mayor que apunta a develar cuál es su significación tanto para los devotos como para quienes descreen de él, en base a tres ejes fundamentales a) Cómo se entiende la existencia y la aceptación de creencias sobre la santidad popular en grupos judíos diaspóricos, b) Cómo en algunas persona se plantea un conflicto y en otras no y c) Cómo se manifiesta un pensar y una sacralidad popular alternativa en que lo judaico está enmarcado en el laberinto del contexto urbano no judío.

Por otra parte, como todo discurso, debe entenderse en relación al contexto, es ineludible no atender también a algunos acontecimientos dentro del panorama económico y social de las dos últimas décadas del siglo XX en Tucumán, que enmarcaron la aparición del culto, un período de grandes cambios y convulsiones entre los cuales señalamos por ejemplo, la finalización del proceso militar, el advenimiento de la democracia, la hiperinflación, la llegada del menemismo y la crisis institucional del gobierno de De la Rúa.

En efecto, a partir de la década de los noventa en Argentina se produjo una explosiva aparición y revitalización de santos populares, un proceso que coincidió con la gestión menemista que impuso la dominación simbólica de la clase dominante al resto del tejido social mediante una economía neoliberal con consecuencias sociales directas, tales como una profunda crisis que impactaría directamente en la vida de los sujetos tanto en los aspectos materiales como espirituales. 
El fenómeno que nos ocupa, entonces, se ubica en la Posmodernidad ya que estos cultos se enraízan especialmente cuando el sujeto está fragmentado a tal punto que busca tener seguridad moral y material, es decir que necesita reconstruirse como un ser total e integrado.

Como bien lo señala Rubén Dri "La globalización que implica el plan neoliberal-conservador en el nivel macroeconómico conlleva un fraccionamiento al infinito de los sectores sociales y en especial de los sectores quienes al estar más abajo en la escala social, sufren una pérdida de identidad alarmante" (Dri, 2007, p. 9).

Quizás por eso el sujeto a menudo busca en el encuentro religioso fuerzas y esperanzas que le permitan sobrellevar la realidad cotidiana. Donde falta trabajo, alimentación y vivienda, donde hasta la educación está deteriorada y la marginación es cosa de todos los días, las diversas formas religiosas en las que se mezclan símbolos y supersticiones de diferentes orígenes pasan a ser una seguridad aparente frente al desamparo de la falta de identidad.

Por su parte, si bien a menudo se señala que la posmodernidad ha desencadenado en el sujeto un proceso de secularización, las manifestaciones de religiosidad popular indicarían lo contrario, porque se advierte una manera de reafirmación de los valores religiosos como un retorno a la relación primitiva del sujeto con el objeto de culto, y en este regreso se busca apaciguar dolencias y necesidades mientras se reafirma una experiencia cotidiana y vital.

\section{La religiosidad popular en el noroeste argentino}

En América Latina, el fenómeno de la religiosidad popular constituye "(...) a unique entry into the logic and cosmovision of Latin American life", como lo señala Graziano, se trata entonces de una práctica que muestra un aspecto integral de cómo se vive la religión en América Latina (Graziano, 2007, p.10). 
O sea que la religiosidad popular puede ser caracterizada como el conjunto de experiencias, actitudes y comportamientos simbólicos que confirman la existencia de lo religioso en la cotidianeidad de los sujetos, una actitud aprendida en edad muy temprana, en el proceso de sociabilización primaria y por eso está íntimamente relacionada con el contexto socio-cultural inmediato.

Argentina, al igual que muchos países latinoamericanos, ha enfatizado maneras de manifestar y configurar lo religioso dentro de las manifestaciones populares, al punto que la creencia en los milagros tiene una gran vigencia actual y se convierte en un fenómeno determinante incluso de la santidad de una persona diferente porque “(...) para la experiencia moderna, el término "milagro” es sinónimo de excepcional e inexplicable. En la experiencia popular el milagro nunca ha dejado de estar a la orden del día, ya que lo espiritual y lo divino integran un continuum y no son compartimentos estancos, se vive la presencia en la tierra de una fuerza mayor que las fuerzas terrenas" (Simán, 2006, p. 47)

En efecto, los prodigios son afines a muchas otras cosmovisiones, siempre tienen un fin concreto, son la posibilidad de otorgar un sentido a la desventura inesperada y al parecer, no tiene una relación simétrica con el grado de cultura o de educación del sujeto, y especialmente cuando se intenta esta vía para curar una dolencia, la afluencia de devotos muestra que hay una enorme crisis de los sistemas de salud, hoy privatizados y regidos por la ley del mercado capitalista.

Al respecto, Fortunato Mallimaci, señala que si bien los profesionales que pasaron por la universidad 'creen' un poco menos que el común de la gente, “(...) las creencias en lo sobrenatural se expanden por toda la sociedad argentina a pesar de que hoy se vive en sociedades capitalistas que están en procesos continuos de secularización. Se trata de una categoría que atraviesa identidades sociales, y determinados conceptos sagrados que dejan de pertenecer a una religión y son usados por cualquier ciudadano según sus creencias, intereses y decisiones"(Clarín, 2010) ${ }^{1}$

En cuanto al noroeste argentino, la religiosidad popular es un campo de resignificación fundamentalmente de la religión católica, “(...) un locus privilegiado de la producción no hegemónica, más 
precisamente el saber o conocimiento local" (Da Silva, 2003, p. 27) porque para este investigador la Iglesia Católica es el ente regulador de las prácticas religiosas y toda manifestación que se aparte de ella es considerada una práctica pagana. De modo que estos cultos son una reacción del sujeto que al no verse contenido en sus marcos, se rebela y reacciona encarando otras relaciones con lo sagrado.

Estamos, pues, en el terreno de las "almas milagrosas", manera como el pueblo designa a los que han sufrido una especie de canonización popular. Son personas fallecidas de forma violenta y que por esa razón, ese dolor y angustia actúan como un elemento purificador que abre las puertas a una cierta sacralización, lo cual los convierte en intermediarios con la dimensión divina.

Así surgen dos categorías: los santos oficiales que son legitimados por la institución por ser modelos de vida, de conducta o de actitud ejemplar ante la muerte y los santos populares que provenientes de un bajo estrato social y económico han tenido una vida sacrificada y por lo general han muerto jóvenes.

Por eso frente a ellos se puede desnudar el alma al punto de pedirles deseos que irían incluso en contra de los principios religiosos cristianos. El santo popular puede conocer e interpretar las verdaderas necesidades de los fieles "(...) se les hacen ofrendas y promesas, se les dedican sacrificios y oraciones (...) en lugares donde nacieron, cayeron muertos o están sepultados, por ello es posible hablar de "tumbas milagreras" sepulturas donde se supone que descansan estos santos y que, en sí mismas son portadoras de poderes especiales" (Barale, 2006, p. 59) práctica que se irradia activamente otros grupos religiosos.

Al parecer, la veneración a los santos es un fenómeno universal evidente en todas las religiones monoteístas. Para el judaísmo, por ejemplo, la búsqueda de la santidad es uno de los objetivos como pueblo elegido lo cual hace que el sujeto busque acercarse a D. consagrarse a su servicio y santificarse mediante el cumplimiento de los preceptos que regulan el hacer y el pensar ético. 
Curiosamente, frente a la organización que se hace en el cristianismo de la santidad como categoría, basada en la representación y en la profusa trasmisión de información sobre un modelo de conducta, en el judaísmo la situación es totalmente opuesta y de cautela y así, al estar prohibida la reverencia de imágenes básicamente por el temor a la idolatría, no se puede construir ni difundir ninguna información accesoria sobre alguien, lo cual lleva a que la religión judía oficialmente no tenga santos.

Sin embargo habría que distinguir la difusión del fenómeno dentro de los dos grandes grupos judíos. Por un lado, ubicamos a la corriente judía sefaradí que al provenir de los países orientales está muy influenciada por los usos islámicos y por esta razón, al igual que los musulmanes reconocen la existencia de algunas santas, si bien por lo general los santos en el judaísmo son varones y estudiosos de la Torá. Por otra parte están las corrientes centroeuropeas ashkenazíes en las que por lo general una persona a la que se le atribuye cierta santidad, tiene una trayectoria con un reconocido liderazgo dentro de un determinado grupo donde sobresalió también por su sapiencia, bondad y dedicación en el estudio de los textos sagrados. Es decir que la condición de santidad emerge de la profundidad y dedicación en el estudio de la Torá, lo cual convierte al sujeto no solo en el ideal supremo de actitudes y conducta religiosas sino también en un inspirador y artífice de algunas tradiciones mortuorias.

Pero la literatura rabínica registra también casos de hombres de extrema piedad, reconocidos más por su santidad que por su estudio, y la evidencia de una vida ejemplar surge de la práctica de valores positivos como la frugalidad, sinceridad, justicia, humildad o castidad. Son individuos reverenciados especialmente por corrientes místicas y cabalísticas.

En efecto nos referimos a los Jasidim, surgidos entre los siglos XIII al XVII en Europa Central y al caso del Baal Shem Tov (El Dueño del Buen Nombre) a quienes se les atribuían poderes sobrenaturales porque se decía que recurrían al nombre secreto de $\mathrm{D}$. para sus milagros e incluso hacían exorcismos basándose en su condición de líderes carismáticos con enorme poder, por eso eran tratados con veneración. 
El Talmud abunda en relatos en los que se emulan los milagros bíblicos, aparece así la figura del "Tzadik", el Justo, un hombre clemente y bondadoso (Jacobs, 1990, p. 121) que a menudo se convierte en un guía espiritual, intermediario entre D. y el hombre. De ahí la importancia que tiene para el devoto estudiar la Torá frente a la tumba de alguien con esas características, ya que esta acción es una posibilidad concreta de acceder incluso a tener visiones de esa persona.

Ahora bien, cuando rastreamos el fenómeno de lo santo y la santidad a través de la historia judía se advierte en ocasiones una permeabilidad social hacia las creencias circundantes incluso de culturas como la musulmana, ya que evidentemente hay circunstancias contextuales que incentivan este tipo de culto, al punto que Ben Ami señala que "Jewish and Muslim saints have many caracter traits in common. Both groups are aware that the saint bears within himself a dual power for good and evil with equal potency" (Ben Ami, 1998, p. 157).

Veamos, entonces cuál era la situación en Marruecos, donde convivían judíos y musulmanes. Allí se consideraba que los santos judíos eran una importante barrera frente a la agresión de la mayoría musulmana y de las reglamentaciones de las autoridades que, por ejemplo les impedían ejercer el comercio, y se cuentan numerosas historias de protección de los santos hacia la comunidad.

Pero tanto la veneración hacia los santos, tanto musulmanes como judíos, serían dos aspectos de un mismo fenómeno, la atribución a alguien como hacedor de milagros. La diferencia estaría que en el primer caso se los considera receptores de una "baraka" una bendición del cielo, mientras que en el segundo se trataría de una condición a la que, como ya señalamos, se llegó por la profundidad en el estudio de la Torá.

En cuanto a la figura de la mujer, tanto en la religión católica como en la musulmana hay una participación femenina más activa que en la religión judía, evidenciada en todo lo vinculado con el culto de los santos ya que aparecen incluso en la creación y propagación de textos escritos como poemas. 
Esta actitud incide evidentemente en la existencia de un gran número de santas dentro de la cultura musulmana del norte de Africa, sin excluir casos de interacción entre judíos y musulmanes como el caso de Cahena, la reina judía de origen bereber que vivió al final del siglo VII y que es citada en Tucumán cuando un informante señalaba que en la tumba milagrosa estaba enterrada "una tal Cadina" readaptación fonética de esta santa popular.

Pero no se llega a neutralizar el predominio masculino: Issachar Ben Ami (1998, p. 13) al analizar la existencia de mujeres santas dentro de la comunidad judía, consigna que en Marruecos de 656 santos muy pocas son mujeres, apenas 35 . $\mathrm{Y}$ este es otro punto que respalda la singular de Malka, ya que la cultura judía casi no registra casos de mujeres que hayan accedido a ese nivel de devoción.

\section{Plegarias atendidas}

En este apartado comenzaremos señalando que el culto de Malka Saltz se diferencia de otras devociones populares de la región porque en su historia no hay un final violento o cruel que nos conmueva desde el sufrimiento. No se trata de alguien joven, cercenado en la plenitud sino que los devotos "malkianos" narran que se trataba de una anciana cuyo cuerpo después de muerta no llegó a corromperse. Es decir que ahí está el primer hito milagroso ya que al quebrarse las leyes físicas y naturales en lo corporal, se manifestaría la presencia del alma especial de quien lo habitó.

Aquí radicaría entonces una de las bases del poderío y persistencia del culto, ya que en nuestras sociedades occidentales el cuerpo es el signo del individuo que lo distingue y separa de los otros, “(...) el cuerpo parece algo evidente, pero nada es, finalmente, más inaprehensible que él. Nunca es un dato indiscutible, sino el efecto de una construcción social y cultural” (Le Breton, 2006, p. 14).

Pero en nuestro caso, al carecerse de una determinada imagen corporal, el cuerpo es dual, por un lado puede funcionar como un límite fronterizo y como factor de individuación, pero por otro, ese cuerpo desconocido que queda, “(...) es la huella más tangible del sujeto en cuanto distiende la trama simbólica y los vínculos que lo conectaban con los miembros de la comunidad" (Le Breton, 2006, p. 153), es decir 
que la fortaleza del alma que estaba dentro de ese cuerpo se extiende al punto de mantener otro tipo de nexo comunitario y se proyecta en el imaginario colectivo.

El cuerpo humano cuando vence las reglas naturales remite a lo sobrenatural, así las santas de la Iglesia mostraban en su cuerpo señales como los estigmas de Cristo para fundamentar que D. las había distinguido, y si bien Malka por su trabajo estaba en contacto con lo impuro, con su muerte y preservación evidencia de alguna manera un contacto directo con el cielo.

Nuevamente insistimos en este punto ya que la resistencia de la materia conlleva el triunfo sobre la muerte y por lo tanto sobre el olvido, porque se trataría de un cuerpo que en su interacción con los otros, ha generado cualidades excepcionales que se evidencian porque contradicen las leyes naturales "(...) y muestra que el relato testimonial de una vida aspira a cumplir, y de hecho así funciona, una función ejemplarizante en una determinada comunidad" (Achúgar, 1992, p. 59).

Cabe señalar que en otra santa popular cristiana como la Difunta Correa también lo milagroso tiene que ver con el cuerpo, el halo de santidad lo da la capacidad de seguir amamantando a su hijo aún después de muerta y en este último caso "(...) se pueden delimitar tres elementos: la leyenda (narraciones que dan cuenta de un suceso realmente acaecido), la creencia (verdades de carácter sacro como vida, muerte, milagros, poderes) y el culto (registros externos como ofrendas, expresiones de agradecimiento, promesas) como lo señala Bibiana del Brutto (Del Brutto, 2007, p. 114).

El caso de Malka tiene también estos tres elementos ya que si bien se trata de un culto más individual y personal, es bastante básico porque no existe un ritual determinado de acercamiento a través de plegarias específicas ni una fecha determinada del año para la peregrinación como Sucot o Lag B'homer, tal como se advierte en otros casos de santidad judía, si bien su tumba el domingo anterior al día del Perdón cuando es usual la visita al cementerio judío, abunda en flores, velas y otros objetos. 
Vemos, pues que el proceso de inferencia desde lo real a lo sobrenatural se sostiene desde estos hechos y también desde las narraciones que hacen los devotos quienes considerando la realización de un trabajo como el lavado de los muertos que, por lo general, es rechazado, concluyen en otras cualidades que enaltecen a Malka como humildad, bondad y sencillez.

Curiosamente, estas actitudes también se advierten entre las santas musulmanas: las hermanas ElKhwatat, Laila Solica Wa'qnin y Laila Sa'ada entregaban pan y aceite a todos los pobres, destacándose por su generosidad (Ben Ami, 1998, p. 26).

El martirologio también es prueba suficiente de santidad, como el caso de la santa judía Sol Ha Tsaddiqqah, conocida también como Solika Hatsadiká, (Solika la Justa) sobre quien André Elbaz señala que se trataba de Sol Hatchuel (1820-1834) una joven judía que prefirió la muerte a la conversión al Islam y casarse con un musulmán. Fue decapitada en Fez y su tumba se convirtió en lugar de peregrinaje.

Otros detalles aúnan a las santas judías con las musulmanas: sus tumbas son modestas y sencillas sin ofrendas ni exvotos. Tampoco son tan visitadas como la de los santos varones, no tienen santuarios en su honor ni días específicos de peregrinación como sucede con los santos varones que incluso tienen asientos para que recen los devotos.

\section{Un cuerpo intocable, un rostro inventable}

La tumba de la santa judía tucumana tiene sus peculiaridades ya desde la disposición general del espacio necrológico, porque los lugares en el cementerio judío local no responden a una organización caprichosa sino que siguen preceptos y leyes.

Ubicada a la derecha de la entrada principal, ya una lectura semiótica nos indica que Malka está en el lado respetado y prestigiado, muy lejos de la izquierda donde se ubica el lado siniestro y rechazado, y 
desde lo visual el lugar también es motivo de atención. El cementerio delimita un espacio que tiene una expresión estética determinada, pero la tumba no se inserta en forma armoniosa en el conjunto general porque tiene colores, antes estaba pintada de blanco y luego le agregaron cerámica celeste para preservarla ${ }^{2}$, y sobresale de las otras que la rodean, carentes de color o uniformadas en los colores de la tierra.

Sin embargo no está sola sino en comunidad, las otras tumbas tienen desgastadas lápidas desde donde emergen nubes de mosquitos y telarañas, y la enmarcan voluminosos árboles que al enroscar sus raíces levantan algunas baldosas y permiten al musgo fosforescente tapizar el suelo. Estamos en uno de los sectores más antiguos del cementerio donde el silencio propende a la manifestación de fuerzas poderosas e inexplicables.

La lápida es rústica y en ella se lee el nombre de la difunta: Malka (Reina) Saltz y la fecha de su fallecimiento (22 de agosto de 1949) pero no hay ninguna imagen, datos de filiación o de origen familiar como ser el nombre de sus padres o de un probable esposo, ni tampoco placas que a modo de homenaje le podrían haber puesto de sus familiares, todo lo cual acentúa aún más su origen misterioso.

Se registra en cambio, que la tumba fue costeada por la Jevrah Kedishe, la asociación comunitaria judía que fiscalizaba la observancia de los sepelios y que en casos de necesidad como suponemos fue este caso, se encargaba de obtener fondos especiales para costear las inhumaciones de los indigentes.

La boleta de inhumación N.596 del registro de inhumaciones de la Jevrah Kedusha Ashkenazí de Tucumán indica que si bien falleció el 19 de agosto, se la enterró el 22 de agosto de 1949 en el cuadro 21, sepultura 69 a los 67 años. No indican su estado civil ni nacionalidad pero sí que se la trajo de la vecina provincia de Santiago del Estero. 
Cabe aclarar que el cementerio judío de esa ciudad se organiza en recién en 1956 y por eso las inhumaciones se hacían en Tucumán o en una de las antiguas colonias judías, Colonia Dora (Santiago del Estero) que ya tenía su necrópolis desde 1844.

Tampoco se sabe si Saltz era su apellido original o el de su cónyuge Isaac (mencionado por un informante) ya que a veces era común que las mujeres judías fueran inhumadas solo con su apellido de casada siguiendo antiguas costumbres europeas.

Además de su ignota historia y de su peculiar culto, uno de los elementos que más singulariza la tumba de Malka es que está llena de elementos provenientes de la imaginería visual propia del noroeste argentino articulada sobre herencias iconográficas, porque presenta numerosos exvotos de agradecimiento, que además de ser propios de la religión católica constituyen pruebas concretas del proceso de inserción cultural de la comunidad judía en el contexto general.

Al respecto Griselda Barale señala que "La tumba de Malka tiene exvotos como las de los milagreros cristianos. He entrevistado a gente que se refería a Malka como si fuera alguien a quien pedirle cuando se tiene un dolor en el corazón como me ha dicho una mujer. Por eso las plaquitas agradecen los favores recibidos" (Entrevista en el diario La Gaceta de Tucumán, 22 - 4 - 2007).

Probablemente por eso, frente a la sobriedad y simpleza icónica que tienen las otras tumbas en el marco general del cementerio, la presencia de este sepulcro tan lleno de imágenes y colores, representa una prueba tangible, un espaldarazo de santidad que confirma su condición. Estos objetos a los que se les asigna cierta eficacia, tienen una función mediadora con las potencias que son inalcanzables de otra manera, son ofrendas, formas simples y primitivas de solicitar la intercesión o de agradecer el pedido para entrar en relación con lo venerado. 
Por otra parte, si bien aparecen las velas, elementos casi infaltables de estos rituales de aproximación, junto con las placas agradeciendo los milagros (aunque sin identificación del devoto) el resto de los objetos que están en la tumba de Malka son, por su mixtura, casi una metáfora de la cultura regional, pero desconocemos si hay exvotos de sacrificio como ayunos, caminatas sobre rodillas, etc, propias de los rituales católicos, porque esas serían actitudes totalmente extrañas a las costumbres judías.

Allí están combinados dentro de una peculiar sintaxis distintas ofrendas que no solo atestiguan la abundancia de las visitas sino que permiten identificar los dos principales orígenes de asistentes: por un lado los elementos generales de uso común (gomillas para el pelo, llaveros, pequeños juguetes, anillos, floreros con flores, relojes, llaves de casas o de automóviles) cuelgan de la estrella de David en lo alto del monumento, y por otro aparecen los elementos propios del ritual judío, (kipot o solideos, piedras de distintos tamaños, cadenas con estrellas de David con una piedra en el centro a modo de talismán, papelitos y manitos con los dedos anudados contra la mala suerte) que se observan también en otros lugares considerados santos tales como el Muro de los Lamentos de Jerusalém, la tumba del Rebe de Lubavich en New York, e incluso otras tumbas de rabinos milagreros en Israel como Rabi Meir Baal Hanes o el Baba Yaga.

En efecto, se trata de un collage polvoriento en el que los resquicios de los vientos dejan trozos de cerámica rotas, hebillas de pelo, flores amontonadas, piedras de colores, rótulos de acrílico con nombres o sin ellos que se cruzan y dialogan sobre las diferentes maneras en que los individuos se vinculan con el pedido y la consiguiente ofrenda, con reapariciones y latencias sociales teñidas de atemporalidad dando a la imagen la sensación de un tiempo que se detuvo eternamente.

Esta abundancia de objetos, texturas, materiales, y colores conforma una mezcla propia de la religiosidad popular, una creación colectiva y anónima próxima a la estética del kitsch, porque sobre la superficie de la tumba se conforma una mezcla de materiales y orígenes, formas y objetos que tienen una significación personal para el ofrendante quien desarrolla su propio ritual frente a la ausencia de alguno específico. 
Las formas se relacionan, la estrella de David que preside la tumba, sirve como soporte para colgar las ofrendas que desnudan los temores humanos y pasa a ser de un espacio de contemplación a un espacio de comunicación, un espacio simbólico que va desde lo privado a lo público, desde lo estático de las formas al dinamismo que le da el observador al hacer la recorrida de los elementos que a veces se oponen, pero no hay símbolos como cruces, provenientes de otra religión como la cristiana.

Nos preguntamos, ¿cómo se desenrolla este mapa de sentidos? Porque frente a este caos de ofrendas solo el espacio disponible es lo que regula la distribución mientras que también el recorrido del receptor es caótico, simultáneo de imagen y sentidos. Si bien algunos elementos se complementan: por ejemplo aparecen objetos propios de la infancia junto a otros de la vida adulta, y así en la mirada del sujeto al recorrer las ofrendas, “(...) el tiempo parece suspendido, los objetos comparten su temporalidad, existen simultáneamente, aunque el discurso por su propia naturaleza deba ordenarlos sucesivamente" (Filinich, 2003, p.17) porque el sujeto las organiza como una coexistencia.

El peregrinaje busca el olor de la santidad desde los lindes, los márgenes y en este sentido la tumba tiene algo de barroco porque como señala Griselda Barale “(...) el barroco pliega y despliega el límite, la frontera, concepto que se entiende como una línea arbitraria (...) que opera como valla o un espacio de interacción cultural, y por eso puede ser corrido, superado" (Barale, 2009, p. 25).

La tumba de Malka nos ubica entonces, ante un claro caso de hibridación cultural entendida, al decir de Bajtín como un procedimiento intencional en el cual se insertan dos lenguajes sociales, dos conciencias lingüísticas diferentes que pasan a dialogar y que García Canclini (2001) completa señalando que así surgen zonas de conflicto en la interculturalidad latinoamericana.

Así se ha conformado un discurso complejo, una geografía que abraza el espacio y que engloba objetos, personas y acciones, una semiosis múltiple cuya metodología de análisis supera la mera aproximación empírica y va más allá de la dimensión estética porque con los objetos se responde a un objetivo claro: 
ayudar a la comunicación con otras esferas y colaborar con el devoto en el proceso en que los sentimientos desplazan a la razón.

Por todas estas razones, la tumba se transforma en un objeto cultural que transmite significados controvertidos, genera consenso fervoroso o disenso rotundo al inscribirse en una trama social general en la que coexiste con una diversidad y multiplicidad de imágenes.

La tumba de Malka muestra oposiciones y simetrías, presencias míticas y heroicas, sagradas y paganas, una amplitud iconográfica en la que el sujeto se apropia de la tradición y se convierte en protagonista de la historia. Así nuestra mirada se prolonga sin límites y se aleja de la función sacralizante y conmemorativa que tiene un monumento funerario, genera sentimientos contradictorios entre quienes lo aceptan y quienes lo rechazan como "avodá zará" (idolatría) y justamente ése es el conflicto que propaga la religiosidad popular, ya que se producen interrelaciones entre las sólidas posiciones de la institución religiosa oficial y las experimentaciones religiosas populares.

Sin embargo, averiguamos cuál es la situación con otra cultura religiosa en Tucumán y advertimos que en el cementerio musulmán este proceso de hibridación no aparece o es más incipiente, a pesar de que algunos van a pedir favores a determinadas tumbas como la de los fallecidos Suleimán, Jattib o "el tío Camilo" tal como nos dijo el guardián del lugar, especialmente estudiantes antes de los exámenes o personas ante un problema de salud, si bien el presidente de la Sociedad Panislámica local señaló que entre ellos no existe una tumba santa.

Tampoco desde lo visual, no hay allí elementos que confirmen un proceso de hibridación, ya que las tumbas están dentro de mausoleos con flores, el libro del Corán, asientos para el asistente, incienso y la foto del fallecido, sin exvotos de agradecimiento o velas. 


\section{Conclusiones}

A menudo el secreto de un fenómeno social se explica no solo desde el análisis de sus componentes sino desde la síntesis que hacen de él quienes, muchas veces sin saberlo, participan en un proceso que tiene mucho de deconstrucción.

Los seguidores de Malka están interviniendo un espacio público comunal, dislocando una escena cercana a la religiosidad popular cristiana y construyendo una escenografía más propia de las artes visuales que del ritual religioso que a la vez toma por asalto al público que, de esta manera, es bidireccional pues incorpora al sujeto (ya sea desde la aceptación o la impugnación) a la propia geografía del espacio mortuorio.

La tumba de Malka es por lo tanto una estrategia de interferencia colectiva que es aceptada por las instituciones religiosas locales, pero también es una propuesta desde los márgenes. Hay roces e hibridaciones que trae el contacto cultural dentro de un espacio fundante para la comunidad judía como el que constituye el cementerio y así a través de este culto, entra la misma calle sin llegar a alterar funcionamiento del espacio sino que por lo contrario, aporta a incrementar el imaginario social instalando una mirada crítica a la institución tradicional.

Lo curioso de este caso es que al fenómeno de Malka Saltz lo rodea un contexto de diversidad y fecundidad de matrices culturales. Es una prueba concreta de la existencia de una permeabilidad local a otras influencias ya que el código funerario judío, que tiende a mantenerse inmune a los cambios y transformaciones, evidencia con la existencia de este ritual mortuorio cierta porosidad, falta de rigidez y de resistencia.

Es decir que pasa a ser la respuesta a un ritual tradicional que no satisface las expectativas del creyente pero que cuenta curiosamente con la aceptación o tolerancia de las autoridades religiosas oficiales que no manifiestan ninguna actitud de impugnación o rechazo a las prácticas tal como señala Amegeiras, 
“(...) la puja y el conflicto por el predominio de unos universos simbólicos sobre otros se traduce tanto en instancias de impugnación y resistencia como en procesos de yuxtaposición, síntesis y sincretismo" (Amegeiras, 2006, p. 377) y en este caso estamos ante la segunda alternativa.

Indudablemente un contexto que exhibe tal permeabilidad, sostiene y favorece la persistencia del culto, constituyendo una religiosidad que incluso a las puertas del siglo XXI conlleva la decepción de los individuos. Se impugnan las instituciones y se inaugura una religiosidad estrechamente vinculada a las necesidades privadas y personales junto a la búsqueda de una interacción dinámica con una entidad desconocida.

La tumba de Malka exhibe una imagen identitaria alternativa, alejada del canon judaico ortodoxo que rechaza el culto y la ofrenda por su sesgo de idolatría. La historia oficial, entonces, acrítica y estereotipada tambalea frente a la realidad del culto y la tumba exhibe las tensiones propias de fragmentaciones e hibridaciones que conforman una sintaxis en la que conviven los aspectos cotidianos y las dimensiones propias de la vida social.

Por todo esto, el culto de Malka Saltz pasa a ser algo totalmente inusual porque la tierra argentina absorbió a una descendiente de inmigrantes y le dio todo, pero ella le dio más porque pasó a ser objeto de culto para todos los argentinos, tanto judíos como no judíos, constituyéndose en el aporte concreto a las identidades culturales de las sociedades americanas ya que muestra la diversidad en el pasado reciente y de alguna manera, permite esbozar el futuro. 


\section{Notas}

${ }^{1}$ La 2008 la Primera Encuesta sobre Creencias y Actitudes Religiosas en Argentina, fue realizada durante 2009 por la Universidad Empresarial Siglo 21 (UES 21) entre 1.027 hombres y mujeres de 18 a 70 años de la Capital Federal, Tucumán, Corrientes, Mendoza, Comodoro Rivadavia, Córdoba y Rosario. Ver el artículo "Siete de cada diez argentinos creen que los milagros existen publicado el 02-08-2010 | Clarín | Sociedad"

${ }^{2}$ El responsable del cementerio fue quien decidió poner cerámica azul sobre la lápida, y cuando le preguntamos por qué lo había hecho, respondió que para que esté más lindo, es decir que en búsqueda de mayor belleza, en él primó que lo que Juan Acha califica como herencia (historia) adquisición (cultura) e importación (dependencia) ya que “(...) en las sociedades actuales circulan ideales y sentimientos, preferencias y aversiones de distinta naturaleza y grado respecto a las categorías estéticas: belleza y fealdad, trivialidad y grandiosidad, tipicidad y novedad" (2000, p. 66) 


\section{Bibliografía}

ACHA, J. Los conceptos esenciales de las artes plásticas. México, Ediciones Coyoacán, 2000.

ACHUGAR, H. "Historias paralelas/ historias ejemplares: la historia y la voz del otro". Revista de Crítica Literaria Latinoamericana. Lima, (36): 26-34,1992.

AMEGEIRAS, A. "Religiosidad popular y MERCOSUR: fecundidad y pluralidad de lo religioso en el cono Sur de América Latina EN: SCANNONE, J.C.,GARCIA DELGADO, D (2006) Ética, desarrollo y región. Hacia un regionalismo integral. Buenos Aires, Argentina, 2006, pp 375-385.

BARALE, G. "Tradición popular en cuatro artistas tucumanos", EN: BELTRAME, C. Manual Tucumán de arte contemporáneo. Hacia la comprensión de nuestro arte en el siglo XXI, Tucumán, Argentina. 2009. pp 20-33.

BEN AMI, I. Saint Veneration among the Jews in Morocco. Michigan, Wayne State University Press, 1998.

DEL BRUTTO, B. "La Difunta Correa" EN: RUBÉN DRI (coord.) Símbolos y fetiches religiosos en la construcción de la identidad popular. Buenos Aires, Editorial Biblos, 2007, pp 15-29.

DRI, R. Racionalidad, sujeto y poder. Irradiaciones de la fenomenología del espíritu. Buenos Aires, Biblos, 2002.

DRI, R. (Coord) Símbolos y fetiches religiosos en la construcción de la identidad popular. Editorial Biblos, Buenos Aires, 2007.

ELBAZ, A. "Le culte des saints dans le conte populaire des sepharades canadiens d'origine marocaine", The Sepharadi and Oriental Jewish Heritage, EN ISSACHAR BEN AMI (ed). Jerusalem. The Magness Press, The Hebrew University, 1982, pp 32-45.

GARCÍA CANCLINI, N. Culturas Híbridas. Estrategias para entrar y salir de la modernidad. Barcelona, Paidós, 2001.

FILINICH, M. I. La descripción. Buenos Aires, Eudeba. 2003 
GRAZIANO, F. "Cultures of Devotion Folks Saints of Spanish America". Oxford, Oxford University Press.2007. Reseña de Todd Hartch, Estudios Interdisciplinarios de América Latina y el Caribe. Universidad de Tel Aviv, Volumen 20 (2): pp 57-59, 2008/2009.

LE BRETON, D. La sociología del cuerpo. Buenos Aires, Nueva Visión, 2002.

SEMÁN, P. La religiosidad popular. Creencias y vida cotidiana. Buenos Aires, Capital Intelectual, 2004.

SEMAN, P. Bajo continuo. Exploraciones descentradas de la cultura popular y masiva, Buenos Aires, Ed Gorla, 2006.

VALENTIÉ, M. E. (coord) Relatos y ceremonias en la religiosidad popular. Tucumán, Universidad Nacional de Tucumán, 2000.

Diario La Gaceta, Tucumán, Argentina, número del 22-4-2007

Diario “Clarín" 02-08-2010 